\title{
Optimalisasi Bank Sampah Berbasis Pemberdayaan Masyarakat di Desa Randegan, Kecamatan Tanggulangin, Kabupaten Sidoarjo
}

\section{Gogor Arif Handiwibowo ${ }^{1^{*}}$, Lissa Rosdiana Noer ${ }^{2}$}

1,2Departemen Manajemen Teknologi, Institut Teknologi Sepuluh Nopember, Surabaya, Indonesia, 60111

E-mail: gogorhandiwibowo@gmail.com

DOI: https://doi.org/10.37339/jurpikat.v1i2.319

\section{Info Artikel:}

Diterima :

2020-10-15

Diperbaiki :

2020-10-28

Disetujui :

2020-10-28

Kata kunci: Pengelolaan Sampah, Bank Sampah, Pemberdayaan Masyarakat, Desa Randegan.

\begin{abstract}
Abstrak: Pengelolaan sampah diperlukan untuk mengurangi produksi sampah. Konsep bank sampah berbasis pemberdayaan masyarakat dianggap mampu mengelola sampah, selain agar volume dapat berkurang, sampah yang ada dapat diubah menjadi lebih bernilai ekonomis. Desa Randegan, Kec. Tanggulangin, Kab. Sidoarjo telah menerapkan konsep bank sampah untuk mengelola sampah yang dihasilkan oleh masyarakatnya. Akan tetapi terdapat permasalahan dimana masih diperlukan peningkatan kapasitas SDM agar pengelola bank sampah dapat secara optimal melakukan pemilahan sampah hingga menghasilkan nilai ekonomis tertinggi. ITS sebagai salah satu institusi pendidikan tinggi di Jawa Timur dengan konsep pengabdian masyarakat berkomitmen untuk memberikan knowledge yang diperlukan untuk pengelolaan sampah secara optimal. Dengan pemberian pelatihan pemilahan jenis-jenis sampah dan pemberian bantuan alat-alat bantu pengelolaan bank sampah maka bank sampah di Desa Randegan dapat lebih baik dalam pengelolaannya.
\end{abstract}

Abstract: Waste management is needed to reduce waste production. The concept of a community empowermentbased waste bank is considered capable of managing waste, in addition to reducing the volume, the existing waste can be converted into more economical value. Randegan Village, Kec. Tanggulangin, Kab. Sidoarjo has 
Keywords: Waste Management, Waste Bank, Community Empowerment, Randegan Village. applied the concept of a waste bank to manage the waste generated by the community. However, there is a problem where it is still necessary to increase the capacity of human resources so that the waste bank manager can optimally sort the waste to produce the highest economic value. ITS as one of the higher education institutions in East Java with the concept of community service is committed to providing the necessary knowledge for optimal waste management. By providing training in sorting the types of waste and providing assistance with waste bank management tools, the waste bank in Randegan Village can be better managed.

\section{Pendahuluan}

Kabupaten Sidoarjo sebagai salah satu kabupaten di Jawa Timur juga mempunyai permasalahan terkait pengelolaan sampah dan lingkungan. Hingga tahun 2019, jumlah sampah yang diproduksi oleh masyarakat Kab. Sidoarjo mencapai sekitar $4.700 \mathrm{~m}^{3}$ per harinya. Sedangkan kemampuan angkut sampah ke TPA hanya maksimal sekitar 25\%. Dengan demikian kira-kira sekitar $3.500 \mathrm{~m}^{3}$ sampah per hari tidak dapat terangkut.Sehingga dimungkinkan sampah yang tidak terangkut tersebut dikelola secara tidak sesuai prosedur lingkungan oleh masyarakat misalnya dibuang ke sungai, dibakar, dimasukkan ke lubang tanah dan lain-lain. Padahal sampah tersebut dimungkinkan terdapat bahan-bahan yang tidak dapat terurai oleh lingkungan dan bahkan bahan-bahan beracun dan berbahaya (B3).

Desa Randegan memiliki luas wilayah 41,1 Ha., yang secara administratif pemerintahan terbagi menjadi 2 RW dan 9 RT dengan jumlah penduduk 4.289 Jiwa. Batas administratif Desa Randegan sebagai berikut:

1. Utara : Desa Ganggangpanjang, Kec. Tanggulangin

2. Selatan : Desa Pesawahan Kec. Porong

3. Barat : Desa Pangkemiri Kec. Tulangan

4. Timur : Desa Ketegan dan Desa Boro, Kec. Tanggulangin

Desa Randegan terdiri dari hamparan dataran tanah darat dan sebagian tanah sawah pertanian. Desa Randegan dilewati oleh 2 aliran sungai di ujung barat hingga ke arah timur desa. Sungai yang ada di sebelah utara sekaligus sebagai batas antara RW 1 dan RW 2 banyak digunakan sebagai sungai buangan air hujan dan rumah tangga. Sedangkan sungai yang ada diselatan digunakan untuk irigasi lahan persawahan. 


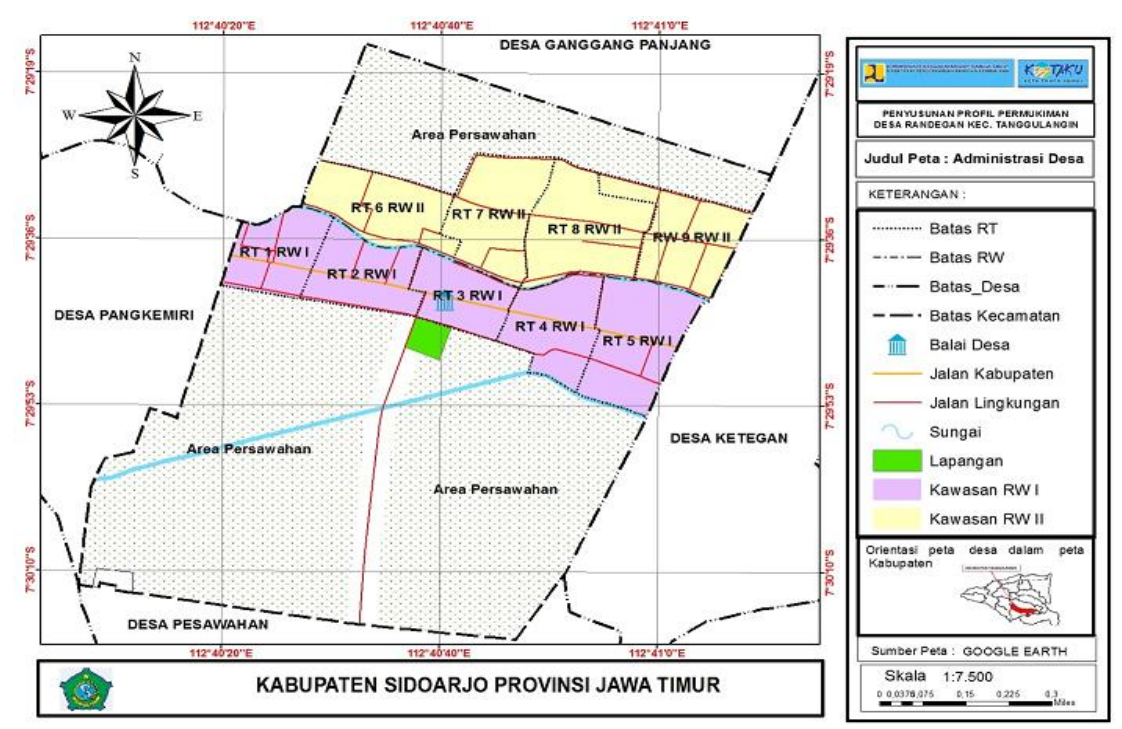

Gambar 1. Peta Desa Randegan - Sidoarjo

Desa Randegan, Kec. Tanggulanin, Kab. Sidoarjo adalah salah satu desa yang telah melaksanakan pengelolaan sampah dengan sistem bank sampah. Bank sampah merupakan suatu konsep pengumpulan sampah yang masih memiliki nilai ekonomis oleh masing-masing anggota (dalam konsep ini disebut dengan nasabah) untuk ditabung (Apriadi, 2012). Sistem bank sampah adalah pengelolaan sampah yang dihasilkan terutama oleh keluarga dimana sampah tersebut akan pilah menjadi 2 bagian besar. Untuk sampah yang berupa organik (sisa makanan, sisa olahan dapur, dll.) kemudian diolah menjadi pupuk yang dapat digunakan untuk media penyuburan tanaman. Adapun sampah yang berupa non organik akan dikelola dengan menggunakan sistem seperti perbankan yang dilakukan oleh petugas relawan (Sucipto, 2012). Penyetor adalah warga yang tinggal di sekitar lokasi bank serta mendapat buku tabungan seperti menabung di bank. Hasil dari pengumpulan sampah yang sudah dipilah akan disetorkan ke tempat pembuatan kerajinan dari sampah atau ke tempat pengepul sampah. Pengelolaan sampah non organik ini yang disebut dengan sistem bank sampah (Suwerda, 2012).

Problema yang dimiliki bank sampah di Desa Randegan adalah kurangnya pengetahuan (knowledge) dalam proses pemilahan sampah, terutama sampah plastik. Dengan kekurangan pengetahuan tersebut, pemilahan sampah plastik tidak dapat dilakukan secara optimal. Walhasil nilai ekonomis yang dihasilakan dalam pemilahan sampah plastik tidak terlalu tinggi. Padahal terdapat potensi dimana saat pemilahan sampah plastik dilakukan dengan benar, maka nilai ekonomis yang didapatkan semakin tinggi sehingga income bank sampah tentu akan semakin tinggi pula. 
Dalam kegiatan pengabdian masyarakat menggunakan dana internal Institut Teknologi Sepuluh Nopember (ITS) - Surabaya topik optimalisasi bank sampah denga konsep pemberdayaan masyarakat dipilih untuk meningkatkan kapasitas bank sampah di Desa Randegan. Diharapkan dengan program pengabdian masyarakat ini secara khusus dapat meningkatkan pendapatan bank sampah dan secara umum dapat meningkatkan kualitas hidup masyarakat Desa Randegan.

\section{Metode}

\section{Strategi}

Dalam melaksanakan Pengabdian Masyarakat dengan kegiatan Peningkatan Kapasitas Sistem Pengelolaan Sampah Berbasis Pemberdayaan Masyarakat Di Desa Randegan - Sidoarjo ini, tim akan bekerja sama dengan mitra organisasi setempat. Mitra yang dimaksud adalah Kelompok Bank Sampah Berkah Abadi Desa Randegan. Selama ini Kelompok Bank Sampah Berkah Abadi hanya menangani pengelolaan sampah di RT 08, RW 02 Desa Randengan. Kelompok Bank Sampah Berkah Abadi ini berencana ingin meluaskan area pengelolaan sampahnya. Terdapat beberapa RT yang ingin bergabung agar sampah yang dihasilknya dikelola oleh bank sampah.

Dalam bermitra dengan Kelompok Bank Sampah Berkah Abadi ini, tim akan bertugas menjadi sumber dana sekaligus pendamping utama dalam proses Peningkatan Kapasitas Sistem Pengelolaan Sampah Berbasis Pemberdayaan Masyarakat Di Desa Randegan - Sidoarjo ini. Sedangkan Kelompok Bank Sampah Berkah Abadi sebagai mitra yang akan menjadi sasaran bantuan di Desa Randegan.

Dalam proses pengabdian masyarakat ini, tim akan menonjolkan pemberdayaan masyarakat. Artinya kegiatan ini masyarakat diajak untuk terlibat secara aktif dalam memutuskan berbagai persoalan yang terkait dengan Sistem Pengelolaan Sampah mulai dari awal hingga akhir.

\section{Perencanaan Kegiatan}

Kegiatan Pengabdian Masyarakat di Desa Randegan ini dibagi menjadi 2 tahap, yaitu tahap perencanaan dan tahap pelaksanaan:

1. Tahap Perencanaan.

a. Identifikasi kebutuhan.

Identifikasi kebutuhan bank sampah di wilayah Desa Randegan Kab. Sidoarjo untuk menganalisa kebutuhan saat ini dan proyeksi mendatang kegiatan pengelolaan bank sampah.

b. Pembuatan RAB. 
Pembuatan RAB (Rencana Anggaran Biaya) dilakukan agar kegiatan dapat dideskripsikan dengan rinci dan jelas. Mulai dari jenis kegiatan sampai dengan jumlah biaya yang harus dikeluarkan.

2. Tahap Pelaksanaan.

a. Pengadaan peralatan pendukung bank sampah.

Pengadaan beberapa peralatan pendukung bank sampah untuk mendukung proses kegiatan operasional bank sampah.

b. Penyuluhan dan pelatihan pengelolaan sampah terpadu.

Memberikan pelatihan pengetahuan terkait pengelolaan sampah terpadu kepada masyarakat agar dapat mengelola sampah yang dihasilkannya serta agar dapat memberikan dampak finansial kepada bank sampah pada khususnya dan anggota bank sampah pada umumnya.

\section{Hasil dan Pembahasan}

Hasil yang dicapai pada kegiatan Pengabdian Masyarakat Peningkatan Kapasitas Sistem Pengelolaan Sampah Berbasis Pemberdayaan Masyarakat Di Desa Randegan - Sidoarjo secara umum telah selesai dalam prosesnya. Baik dilihat dari proses pengadaan alat dan penyerahan maupun konsep pelatihan penanganan sampah. Ceremonial serah terima bantuan disajikan pada Gambar 2.

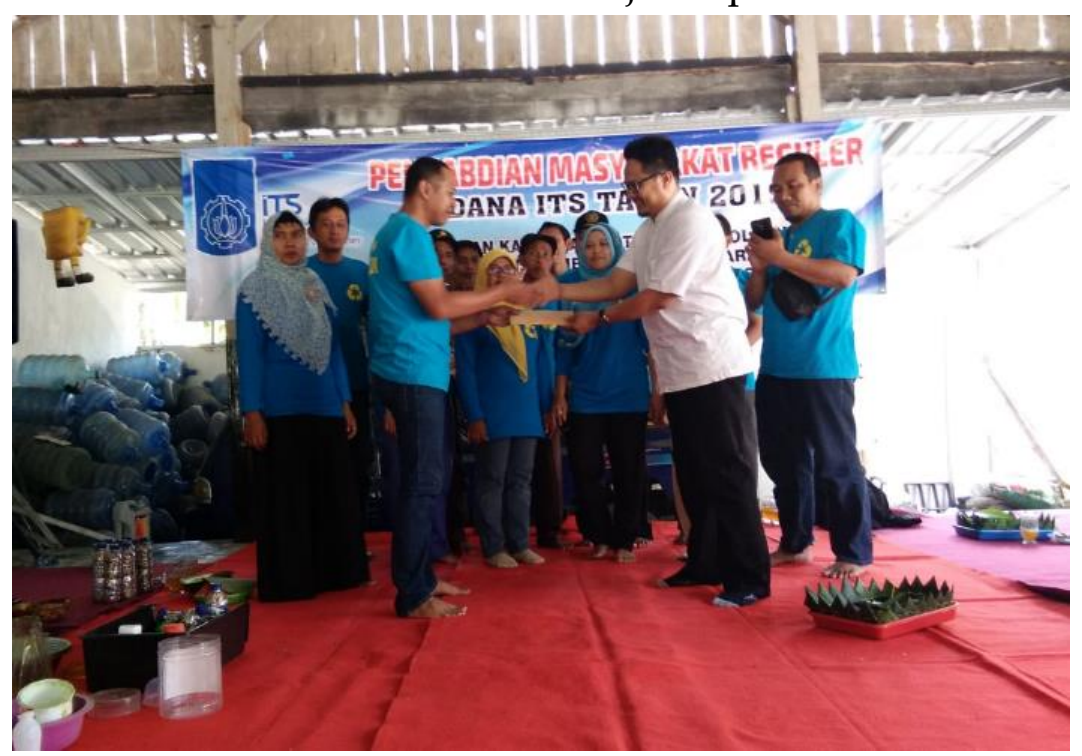

Gambar 2. Ceremonial serah terima bantuan.

Adapun peralatan penunjang kegiatan bank sampah yang telah diberikan antara lain:

1. Timbangan duduk kapasitas $150 \mathrm{~kg}$.

2. Timbangan gantung kapasitas $50 \mathrm{~kg}$. 
3. Timbangan gantung kapasitas $25 \mathrm{~kg}$.

4. Etalase kaca.

5. Perlengkapan savety sepatu boot dan sarung tangan kain

Selain peralatan penunjang kegiatan bank sampah, dilakukan pula pelatihan pengelolaan bank sampah. Adapun materi pelatihan yang diberikan antara lain:

1. Pemilahan sampah plastik

Pemilahan sampah plastik diperlukan oleh bank sampah mitra karena sementara ini, sampah plastik yang didapatkan dari anggota maupun masyarakat kurang dipilah. Padahal pemilahan sampah plastik berdasarkan jenis plastik dapat meningkatkan nilai jual yang berdampak pada peningkatan pendapatan organisasi bank sampah. Dengan materi pelatihan pengenalan jenis-jenis plastik diharapkan kedepan pengelola dan anggota bank sampah dapat mengidentifikasi berbagai jenis sampah plastik serta memilahnya. Hasil pemilahan sampah plastik ini kemudian dijual ke pengepul besar atau ke industri plastik yang membutuhkannya. Pelatihan pemilahan sampah plastic disajikan pada Gambar 3.

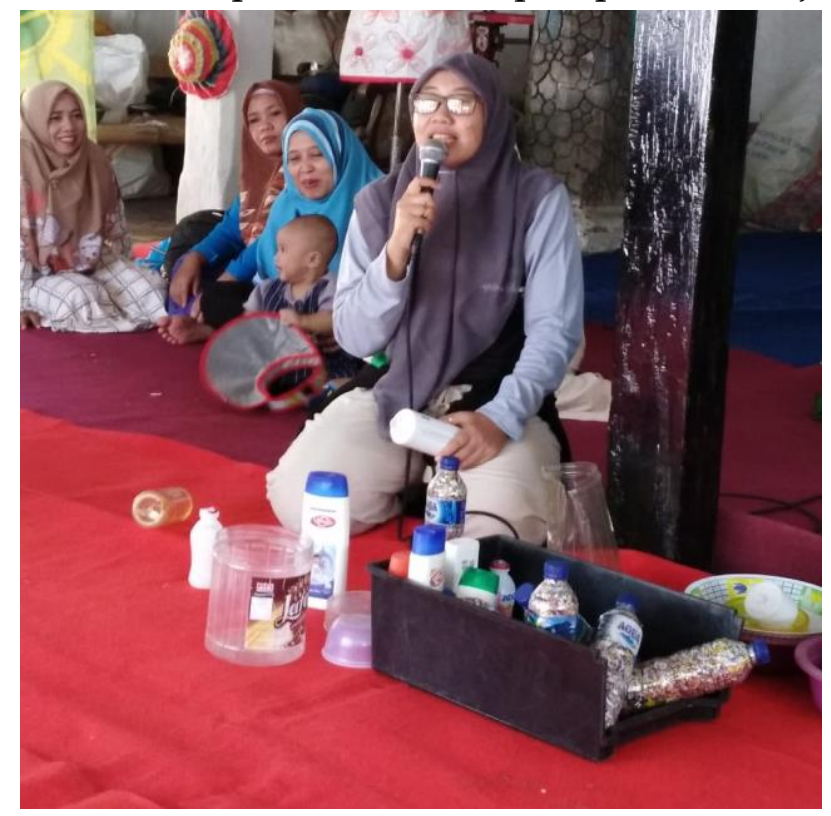

Gambar 3. Pelatihan pemilahan sampah plastik

2. Pemanfaatan sampah untuk produk kreasi

Sampah selain dipilah untuk kemudian dijual ke pengepul besar atau industri yang membutuhkannya juga dipilah untuk dimanfaatkan menjadi produkproduk kreasi yang memiliki nilai ekonomis yang tinggi. Pelatihan pemanfaatan sampah untuk produk kreasi yang diberikan antara lain seperti pemanfaatan plastik bekas untuk dibuat produk meja kursi, baju kreasi sampah, produk peralatan rumah tangga dan lain-lain. 


\section{Keberlanjutan}

Kegiatan Peningkatan Kapasitas Sistem Pengelolaan Sampah Berbasis Pemberdayaan Masyarakat Di Desa Randegan - Sidoarjo mempunyai titik tekan pemberdayaan. Artinya ada proses transfer pengetahuan bagaimana masyarakat belajar melakukan proses pembangunan di wilayahnya secara mandiri. Bentuk transfer pengetahuan itu terjadi dalam rangkaian rembuk warga dan pengambilan keputusan didalamnya.

Sesuai dengan hasil yang telah dicapai, maka aksi keberlanjutannya adalah antara lain:

1. Melakukan rembuk bersama didalam kepengurusan bank sampah terkait optimalisasi bantuan alat yang telah diterima. Optimalisasi yang dimaksud adalah bagaimana caranya agar alat ini dapat digunakan dalam kegiatan bank sampah seperti penimbangan hasil pengumpulan sampah di masing-masing nasabah yang berasal dari rumah tangga, RT hingga RW, pemilahan sampah sesuai dengan klasifikasi sampah yang telah didapatkan melalui pelatihan dan penjualan sampah yang telah diklasifikasi hingga mendapatkan nilai jual yang paling tinggi.

2. Melakukan sinergi antara pengurus bank sampah dengan pengurus RT \& RW di Desa Randengan. Sinergi ini dimaksudkan agar bank sampah bisa mendapatkan akses ke masing-masing RT \& RW untuk mendapatkkan nasabah hingga melakukan pemungutan sampah dari masing-masing nasabah.

3. Pengurus bank sampah mulai membentuk road map kegiatan bank sampah hingga tiga tahun kedepan. Road map ini dimaksud untuk dapat memberikan visi bagi bank sampah apa yang akan diraih dimasa mendatang dan kegiatankegiatan apa saja yang harus dilakukan agar target di masing-masing tahun dapat tercapai.

\section{Kesimpulan}

Pada kegiatan Pengabdian Masyarakat Peningkatan Kapasitas Sistem Pengelolaan Sampah Berbasis Pemberdayaan Masyarakat Di Desa Randegan Sidoarjo dapat disimpulkan sebagai berikut:

1. Secara umum bantuan Peningkatan Kapasitas Sistem Pengelolaan Sampah Berbasis Pemberdayaan Masyarakat Di Desa Randegan - Sidoarjo telah selesai dengan baik. Performa kegiatan ini dapat dilihat dalam beberapa hal antara lain peran serta aktif masyarakat dalam proses perumusan, pelaksanaan hingga pasca pelaksanaan kegiatan. 
2. Konsep pemberdayaan masyarakat pada pengabdian masyarakat ini dapat dicapai. Wujud kongkrit pemberdayaan masyarakat dapat dilihat bahwa masyarakat secara antusias mendukung secara penuh seluruh kegiatan pengabdian masyarakat ini.

\section{Ucapan Terima Kasih}

Ucapan terimakasih kami haturkan ke beberapa komponen yang telah mendukung proses Pengabdian Masyarakat ini sebagai berikut:

1. Rektor Institut Teknologi Sepuluh Nopember (ITS) beserta jajarannya

2. Direktur Direktorat Riset dan Pengabdian Masyarakat (DRPM) - ITS

3. Kepala Desa Randegan beserta jajarannya

4. Pengurus Bank Sampah Berkah Abadi - Randegan, Sidoarjo.

\section{Referensi}

Ambarwati, R., Mudjib, A.W., Lestariani, F.F. \& Handiwibowo, G.A., 2019, The Implications of Good Governance of Village Government Office in Sidoarjo, Binus Business Review, vol. 10, no. 3, pp. 147-158.

Apriadi, P., 2012, Bank Sampah dan Program Lingkungan Yayasan Unilever. http//www.unilevergreenandclean.co.id/greenandclean. Yayasan Unilever Indonesia.

Handiwibowo, G.A., 2015, Kajian Implementasi Corporate Citizenship Dan Corporate Shared Value Melalui Sudut Pandang Triple Bottom Line, Seminar Nasional Manajemen Teknologi 23 (MMT - ITS), A-81-1.

Handiwibowo, G.A., 2018, Singkronisasi Aktifitas Corporate Social Resposibility (CSR) Dan Community Development (CD) Dalam Konteks Pembangunan Berkelanjutan Di Indonesia," IPTEK J. Proc. Ser., vol. 0, no. 5, p. 111, doi: 10.12962/j23546026.y2018i5.4430.

Handiwibowo, G.A. \& Suef, M., 2019, The Impact of Outbound Training Activity on Organization Mission Statement (Case in Education Mission Statement MMTITS), IPTEK The Journal for Technology and Science, vol. 29, no. 1. pp. 25-30.

Handiwibowo, G.A., Noer, L.R., Ambarwati, R., \& Arumsari, Y.K., 2020, Determining the local community indicators on corporate social responsibilitiy activities (case study in Indonesia). $\{I O P\}$ Conference Series: Earth and Environmental Science, 423, 12017. https://doi.org/10.1088/17551315/423/1/012017

Jastam, M.S., 2015, Pemberdayaan Masyarakat Melalui Pengelolaan Sampah (Studi Kasus di Bank Sampah Pelita Harapan, Kelurahan Ballaparang, Kecamatan Rappocini, Makassar, J. Hig., vol. 1, no. 1, pp. 42-47. 
Noer, L.R., Handiwibowo, G.A., \& Syairudin B., 2020, Pemanfaatan Alat Pengusir Burung untuk Meningkatkan Produktifitas Pertanian di Kecamatan Sukolilo Surabaya, SEWAGATI, vol. 4, no.1, pp. 38-42.

Sucipto, C. D., 2012, Teknologi Pengelolahan Daur Ulang Sampah. Yogyakarta: Goysen.

Suwerda, B., 2012, Bank Sampah Kajian Teori dan Penerapannya. Yogyakarta: RihamaRohima. 